\title{
Author Index Vol. 95, No. 1, 1996
}

Asbeck, B.S. van 49 Bel, A. 63 Biemba, G. 78 Cabantchik, Z.I. 70 Castellano, A. 66 Choudhury, R. 6 Cozza, R. 66 Deb,G. 66 Dehkordi, L.S. 6 DeSio, L. 66 Donfrancesco, A. 66 Gabutti,V. 26 Glickstein, H. 70 Golenser, J. 70 Gordeuk,V.R. 78

Hershko,C. 5,87 Hider,R.C. 6 Link,G. 87 Loyevsky, M. 70 Mabeza, G.F. 78 Martinod, E. 63 Marx, J.J.M. 49 Menasché, P. 63 Olivieri, N.F. 37 Piga,A. 26 Pinson, A. 87 Porter, J.B. 13 Rai,B.L. 6 Singh, S. 6 Tsafack, A. 70 